\title{
PRODUCTION AND BIOLOGICAL ACTIVITIES OF A NEW ANTIFUNGAL ANTIBIOTIC, TAN-950 A
}

\author{
Seiji Hakoda, Shigetoshi Tsubotani, Takashi Iwasa, \\ Masaru Suzuki, Masahiro Kondo and Setsuo Harada \\ Research and Development Division, Takeda Chemical Ind. Ltd., \\ 17-85, Jusohonmachi 2-chome, Yodogawa-ku, Osaka 532, Japan \\ (Received for publication October 24, 1991)
}

\begin{abstract}
A novel antifungal antibiotic, TAN-950 complex, was isolated from the culture filtrate of Streptomyces platensis A-136 (IFO 14603, FERM BP-1786). The water-soluble amphoteric substances in this complex were purified by chromatography using ion-exchange resins, QAE-Sephadex and adsorptive resins and were designated TAN-950 A and TAN-950 A $\sim$ E mixture. The molecular formula of TAN-950 A was determined to be $\mathrm{C}_{6} \mathrm{H}_{7} \mathrm{~N}_{2} \mathrm{O}_{4} \mathrm{Na}$ for the sodium salt. This new amino acid antibiotic showed antifungal activity against Candida albicans in vitro and in vivo, and had low toxicity in mice.
\end{abstract}

In the course of screening for new antifungal antibiotics, a strain of Syreptomyces platensis was selected for isolation of its antifungal metabolite. From the broth filtrate, a fat-soluble component having wide antifungal activity was firstly isolated and identified as a known antifungal antibiotic, trichostatin $\mathrm{A}^{1}$. The aqueous layer after extraction with ethyl acetate (EtOAc) also showed antifungal activity especially against Candida albicans in the diffusion assay. Thus, an amphoteric substance, TAN-950 A, was isolated as a new amino acid antibiotic. The chemical structure of TAN-950 A was determined to be (S)-2-amino-3-(2,5-dihydro-5-oxo-4-isoxazolyl)propanoic acid as is shown in Fig. $1^{2}$.

This paper deals with the taxonomy of the producing organism and the production and antifungal activities of TAN-950 A.

\section{Materials and Methods}

Taxonomic Studies on the Antibiotic-producing Strain

Methods adopted by the International Streptomyces Project (ISP) were used for taxonomic characterization and carbohydrate utilization studies. The color notations are those of the Color Harmony Manual, 4th Ed. ${ }^{3)}$. Observations were made after incubation at $28^{\circ} \mathrm{C}$ for 21 days. The procedure of LECHEVALIER was used to prepare the cells and chromatographically detect the isomers of diaminopimelic acid.

\section{In Vitro Antifungal Acivity}

The antifungal activity of TAN-950 A was determined on yeast nitrogen base (Difco) supplemented with $2 \%$ glucose and $1.5 \%$ agar. A conventional agar dilution method was used. The MIC for filamentous fungi and yeasts was expressed in terms of $\mu \mathrm{g} / \mathrm{ml}$ after incubation for $48 \sim 72$ hours at $28^{\circ} \mathrm{C}$.

Amino Acid Antagonism

Antagonism of amino acids was determined on yeast nitrogen base (Difco) supplemented with $2 \%$ glucose and $1.5 \%$ agar. A testing amino acid was included in an assay medium. A conventional agar diffusion method was used.
Fig. 1. Structure of TAN-950 A<smiles>N[C@@H](Cc1c[nH]oc1=O)C(=O)O</smiles> 
Protective Effect in Mice

Five-week old female CF $¥ 1$ mice were given an intravenous injection of $1 \times 10^{6} \mathrm{cfu}$ of $C$. albicans TA, and antibiotics were administered orally or subcutaneously 0 and 2 hours later. ED 50 (total dose giving $50 \%$ survival) values were calculated from the survival rate 7 days after infection.

\section{Results}

\section{Taxonomy of the Producing Strain}

The producing organism, strain A-136, was isolated from a soil sample collected in West Germany. The vegatative mycelia were well developed. Aerial mycelia were branched and formed spiral chains of spores. Mature spore chains had 10 or more spores per chain. The spores were elliptical and measured $0.8 \sim 1.2 \times 0.9 \sim 1.3 \mu \mathrm{m}$, with a smooth surface as shown in Fig. 2. Sporangia, flagellated spores and sclerotic granules were not observed.

The culture characteristics of strain A-136 grown on various media at $28^{\circ} \mathrm{C}$ for 21 days are shown in Table 1. The aerial mass color was in the gray color series. The color of the reverse side of the colonies was pearl gray to light yellowish brown.

The physiological characteristics of strain A136 are presented in Table 2. Strain A-136 grew at $10 \sim 36^{\circ} \mathrm{C}$ with an optimum temperature of $28 \sim$ $32^{\circ} \mathrm{C}$ on yeast extract agar. No melanoid pigment was formed in peptone yeast extract-iron agar or

Fig. 2. Scanning electron micrograph of spore chains of strain A-136.

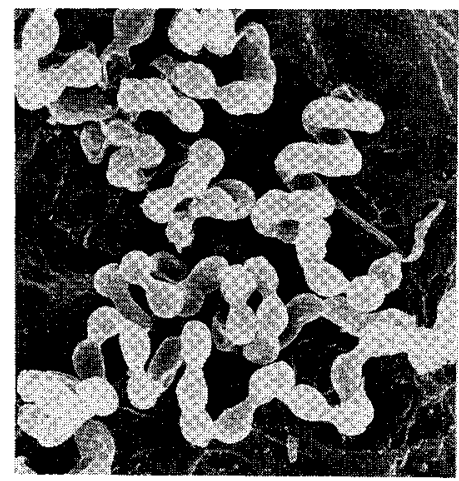

Yeast extract -malt extract agar, 10 days $(\times 8,000)$.

Table 1. Cultural characteristics of strain A-136.

\begin{tabular}{|c|c|c|c|c|}
\hline Medium & Growth & Aerial mycelium & $\begin{array}{l}\text { Reverse side } \\
\text { of colony }\end{array}$ & $\begin{array}{l}\text { Soluble } \\
\text { pigment }\end{array}$ \\
\hline Sucrose-nitrate agar & $\begin{array}{l}\text { Moderate, } \\
\text { spreading }\end{array}$ & $\begin{array}{l}\text { Poor } \\
\text { Pearl (3ba) to light gray (3dc) }\end{array}$ & Pearl (3ba) & None \\
\hline Glucose - asparagine agar & $\begin{array}{l}\text { Moderate, } \\
\text { restricted }\end{array}$ & $\begin{array}{l}\text { Poor } \\
\text { Pearl (3ba) }\end{array}$ & $\begin{array}{r}\text { Pale yellow ( } 2 \mathrm{ca}) \\
\text { to yellow (2ea) }\end{array}$ & None \\
\hline Glycerol - asparagine agar & $\begin{array}{l}\text { Good, } \\
\text { spreading }\end{array}$ & $\begin{array}{l}\text { Abundant } \\
\text { White to light gray ( } 3 \mathrm{dc})\end{array}$ & $\begin{array}{c}\text { Pale yellow }(2 \mathrm{ca}) \\
\text { to beige }(3 \mathrm{ec})\end{array}$ & None \\
\hline Inorganic salts - starch agar & Good & $\begin{array}{l}\text { Abundant } \\
\text { White to light gray ( } 3 \mathrm{dc} \text { ) } \\
\text { to pale brownish gray } \\
\text { (3fe) with black moist } \\
\text { patches }\end{array}$ & $\begin{array}{l}\text { Yellow (2ea) to } \\
\text { yellowish brown } \\
(2 \mathrm{gc}) \text { to black }\end{array}$ & None \\
\hline Nutrient agar & $\begin{array}{l}\text { Moderate, } \\
\text { restricted }\end{array}$ & $\begin{array}{l}\text { Poor } \\
\text { Pearl (3ba) }\end{array}$ & $\begin{array}{l}\text { Pearl (3ba) to } \\
\text { beige (3ec) }\end{array}$ & None \\
\hline Yeast - malt agar & $\begin{array}{l}\text { Good, } \\
\text { spreading }\end{array}$ & $\begin{array}{l}\text { Abundant } \\
\text { White to pale brownish } \\
\text { gray (3fe) to gray ( } 5 \mathrm{fe}) \\
\text { with black moist patches }\end{array}$ & $\begin{array}{c}\text { Pale yellow }(2 \mathrm{ca}) \\
\text { to yellowish } \\
\text { brown }(2 \mathrm{ng})\end{array}$ & Light brown \\
\hline Oatmeal agar & $\begin{array}{l}\text { Good, } \\
\text { spreading }\end{array}$ & $\begin{array}{l}\text { Abundant } \\
\text { Pearl ( } 3 \text { ba) to pale } \\
\text { brownish gray ( } 3 \mathrm{fe}) \text { with } \\
\text { black moist patches }\end{array}$ & $\begin{array}{l}\text { Pearl (3ba) to } \\
\text { pale yellow (2ca) }\end{array}$ & None \\
\hline
\end{tabular}


Table 2. Physiological properties of strain A-136.

\begin{tabular}{|c|c|c|}
\hline \multicolumn{2}{|c|}{ Temperature range for growth } & $10 \sim 36^{\circ} \mathrm{C}$ \\
\hline \multicolumn{2}{|c|}{ Optimum temperature for growth } & $28 \sim 32^{\circ} \mathrm{C}$ \\
\hline \multicolumn{3}{|l|}{ Melanoid pigment } \\
\hline \multicolumn{2}{|l|}{ Peptone-iron agar } & Negative \\
\hline \multicolumn{2}{|l|}{ Tyrosine agar } & Negative \\
\hline \multicolumn{2}{|l|}{ Starch hydrolysis } & Positive \\
\hline \multicolumn{2}{|l|}{ Gelatin liquefaction } & Positive \\
\hline \multicolumn{2}{|l|}{ Milk peptonization } & Negative \\
\hline \multicolumn{2}{|l|}{ Nitrate reduction } & Negative \\
\hline \multicolumn{3}{|c|}{ Type of diaminopimelic acid } \\
\hline \multicolumn{3}{|c|}{ Carbon source utilization of } \\
\hline Good utilization: & \multicolumn{2}{|c|}{$\begin{array}{l}\text { D-Glucose, D-fructose, } \\
\text { raffinose, inositol, mannitol }\end{array}$} \\
\hline $\begin{array}{l}\text { Fair utilization: } \\
\text { No utilization: }\end{array}$ & L-Arabinose, & nose \\
\hline
\end{tabular}

tyrosine agar.

Carbon source utilization by strain A-136 was examined on ISP medium 9. The pattern of carbon utilization by strain A-136 is shown in Table 2 . Inositol, D-mannitol, D-glucose, D-fructose, raffinose, and L-arabinose were utilized, but rhamnose and sucrose were not. LL-Diaminopimelic acid was detected in whole cell hydrolysates of the culture.
Fig. 3. Time course of TAN-950 A production.

Glucose $(\boldsymbol{\Delta})$, potency $(\bullet)$, packed cell volume $(0)$ and $\mathrm{pH}(\square)$.
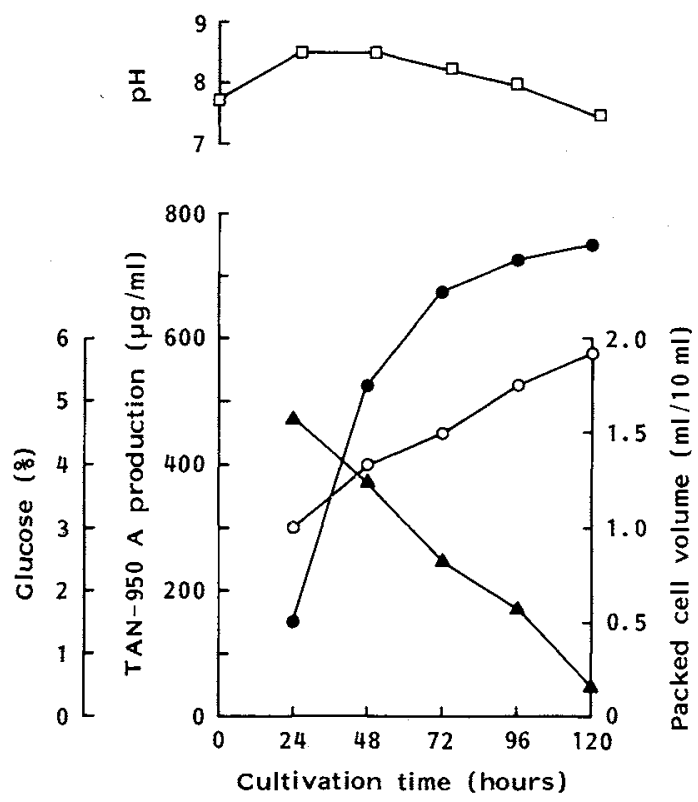

Based on the taxonomic properties described above, strain A-136 was considered to belong to the genus Streptomyces. Therefore, the characteristics of the strain were compared with published descriptions of various Streptomyces ${ }^{4,5)}$. Consequently, strain A-136 was designated Streptomyces platensis A-136.

\section{Fermentation}

A slant culture of strain A-136 was inoculated into a 2-liter flask containing $500 \mathrm{ml}$ of the seed culture medium consisting of $2 \%$ glucose, $3 \%$ soluble starch, $1 \%$ soybean flour, $1 \%$ corn steep liquor, $0.5 \%$ Polypeptone (Daigo Nutritive Chem., Ltd.), $0.3 \% \mathrm{NaCl}$ and $0.5 \% \mathrm{CaCO}_{3}$ and adjusted to $\mathrm{pH} 7.0$ before sterilization. The flask was incubated on a reciprocal shaker at $28^{\circ} \mathrm{C}$ for 48 hours. Five hundred $\mathrm{ml}$ of the seed culture were transferred to a 50 -liter fermenter containing 30 liters of the seed culture medium supplemented with $0.05 \%$ Actocol (Takeda Chem. Inc.). The seed culture was carried out at $28^{\circ} \mathrm{C}$ for 48 hours under aeration of 30 liters/minute and agitation of $280 \mathrm{rpm}$.

Six liters of the seed culture were transferred to a 200 -liter fermenter containing 120 liters of the fermentation medium consisting of $0.5 \%$ glucose, $5 \%$ dextrin, $3.5 \%$ soybean meal, $0.7 \% \mathrm{CaCO}_{3}$, and $0.05 \%$ Actocol and adjusted to $\mathrm{pH} 7.0$ before sterilization. The fermentation was carried out at $28^{\circ} \mathrm{C}$ for 90 hours under aeration of 120 liters/minute and agitation of $200 \mathrm{rpm}$. Glucose was determined by the glucose oxidase system. The growth was determined by packed cell volume. The progress of fermentation was monitored by checking the size of the inhibition zone using Candida albicans.

The time course of antibiotic production in a 200 -liter fermenter is shown in Fig. 3. Antibiotic production reached about $750 \mu \mathrm{g} / \mathrm{ml}$ at 120 hours after inoculation.

\section{Isolation}

Fig. 4 summarizes the procedure for the isolation of the component of TAN-950 complex. The culture 
Fig. 4. Isolation procedure for TAN-950 A.

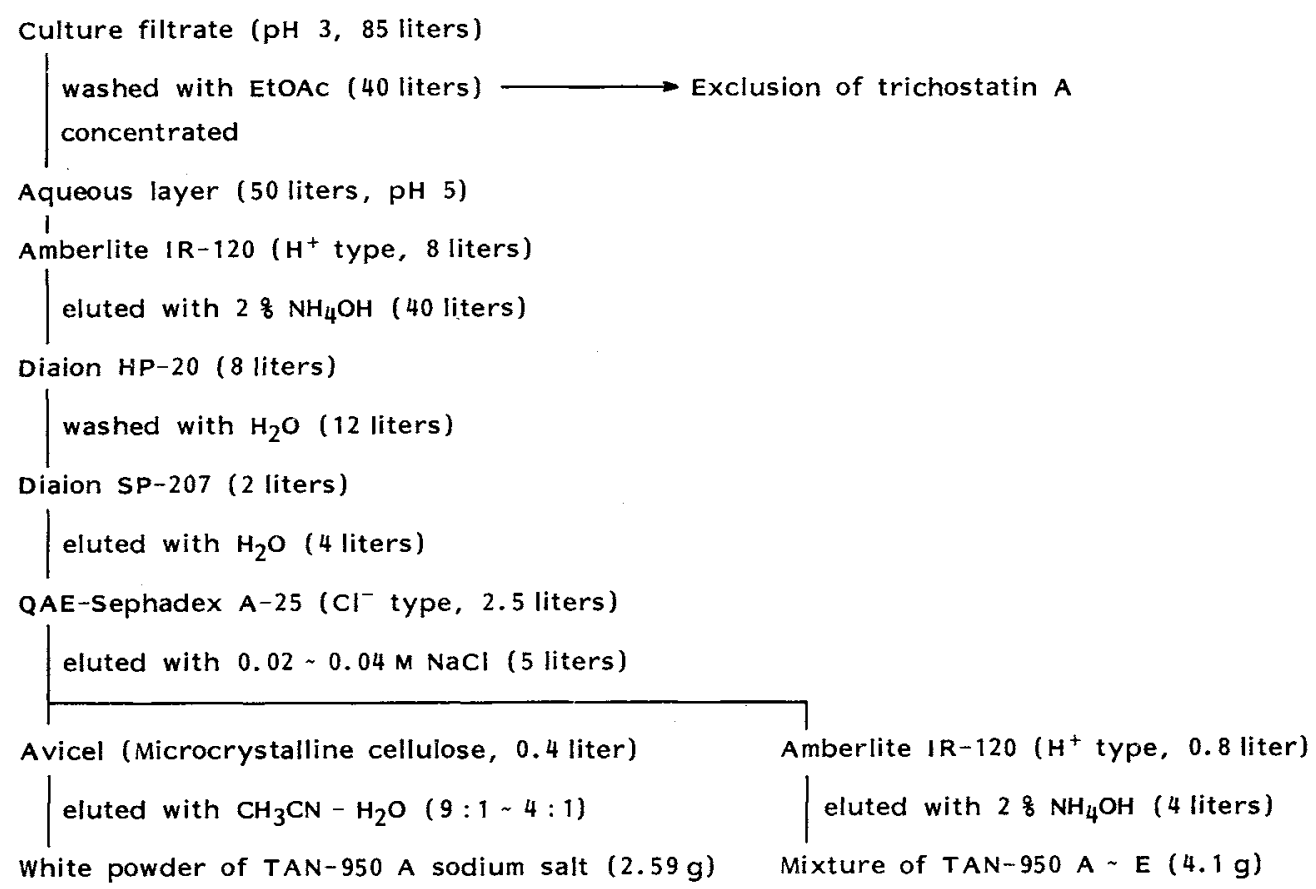

broth (100 liters) was adjusted to pH 8 and filtered using a Hyflo Super Cel. The filtrate ( 85 liters) adjusted to $\mathrm{pH} 3$ was washed with EtOAc. The concentrate of the aqueous layer was applied at $\mathrm{pH} 5$ to a column of Amberlite IR-120. An antibiotic was eluted with $2 \%$ aqueous ammonia, and the eluate was concentrated. The concentrate was passed through a column of Diaion HP-20 washed with water. The concentrate of the effluent was chromatographed on a column of Diaion SP-207 eluting with water. The bioactive fractions were chromatographed on a column of QAE-Sephadex A-25 eluting with $0.02 \sim 0.04 \mathrm{M} \mathrm{NaCl}$. The pure fractions detected by HPLC were combined, concentrated and chromatographed on microcrystalline cellulose eluting with acetonitrile - water $(9: 1$ to $4: 1)$ to afford a white powder of TAN-950 A as the monosodium salt $(2.59 \mathrm{~g})$.

Upon QAE-Sephadex A-25 chromatography, fractions containing mainly TAN-950 B, C, D and E were combined and applied to a column of Amberlite IR-120 ( $\mathrm{H}^{+}$type, 0.8 liter) eluting with $2 \%$ aqueous ammonia. The eluate was concentrated and lyophilized to give a white powder of a mixture of TAN-950 $\mathrm{A} \sim \mathrm{E}(4.1 \mathrm{~g})$.

Fig. 5 shows HPLC patterns of these antibiotics whose retention times (minutes) were TAN-950 A, 6.2; B, 7.3; C, 8.5; D, 9.5 and E, 12.3 under these conditions. The ratio of the peak areas estimated by HPLC analysis was $A: B: C: D: E=2: 1: 2: 1: 2$. We tried to separate TAN-950 B, C, D and E by preparative HPLC, but could not because isomerization proceeded rapidly. Table 3 shows the stability of TAN-950 A in phosphate buffer of various pHs. TAN-950 A reached an equilibrium state after about one hour. The chemical conversion is described in the previous paper ${ }^{21}$.

\section{Chemical Characterization of TAN-950 A}

TAN-950 A was isolated as the sodium salt. It is soluble in water, dimethyl sulfoxide and methonal, 
Fig. 5. HPLC pattern of TAN-950 A and A $\sim$ E mixture.

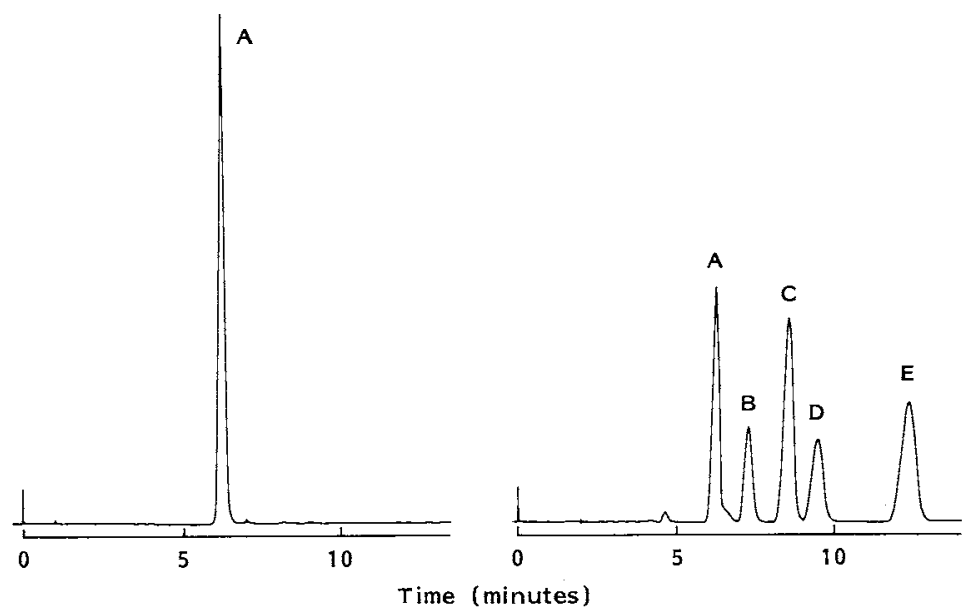

Column, ODS, YMC-Pack AQ-312 (Yamamura Chem. Lab.); mobile phase, $0.25 \mathrm{~mm}$ $n-\mathrm{Bu}_{4} \mathrm{~N}^{+} \mathrm{OH}^{-} / 0.02 \mathrm{M}$ phosphate buffer ( $\mathrm{pH} 6.0$ ); flow rate, $2 \mathrm{ml} /$ minute; detection, absorbance at $214 \mathrm{~nm}$.

and sparingly soluble in acetone, ethyl acetate and chloroform. It gave positive color reactions with ninhydrin and Ehrlich reagents, and negative color reactions with Dragendorff and Greig-Leaback reagents.

The physico-chemical properties of TAN-950 $A$ are summarized in Table 4. The specific rotation of TAN-950 A in water is $-69.5^{\circ}$. The UV spectrum indicated a maximum at $253 \mathrm{~nm}$, suggesting the presence of an $\alpha, \beta$-unsaturated carbonyl group. The molecular formula of TAN-950 A was determined to be $\mathrm{C}_{6} \mathrm{H}_{7} \mathrm{~N}_{2} \mathrm{O}_{4} \mathrm{Na}$ on the basis of elemental analysis, secondary ion mass spectrum (SI-MS) and ${ }^{13} \mathrm{C}$ NMR data. The structure determination of TAN-950 A is described in another paper ${ }^{2}$.

\section{Biological Activity}

MICs for TAN-950 A against 10 different molds and yeasts are shown in Table 5. TAN-950 A showed strong activity against several yeasts with MIC values of $0.78 \sim 3.13 \mu \mathrm{g} / \mathrm{ml}$. However, growths of molds tested were not inhibited at the concentration of $100 \mu \mathrm{g} / \mathrm{ml}$.

It was found also that the activity against yeasts was not observed in Sabouraud dextrose agar. The effect of amino acids on the activity of TAN-950 A was examined. Of the amino acids tested, glutamic acid, aspartic acid and leucine greatly reduced the antifungal activity of TAN-950 A as shown in Table 6.

In vivo antifungal activity of subcutaneously (sc) and orally (po) administrated TAN-950 A was examined in mice with a systemic Candida albicans TA infection. The activity of miconazole was used for comparison, and the date are shown in Table 7. TAN-950 A showed $50 \%$ effective doses against systemic candidiasis at $35.5 \mathrm{mg} / \mathrm{kg}$ (sc) and $100 \mathrm{mg} / \mathrm{kg}$ (po). The efficacy was slightly weaker than that of miconazole.

TAN-950 A did not cause any toxic changes in mice during a 2-week observation period following 
Table 4. Physico-chemical properties of TAN-950 A sodium salt.

\begin{tabular}{|c|c|}
\hline Appearance & White powder \\
\hline Nature & Water-soluble amphoteric substance \\
\hline Optical rotation & {$[\alpha]_{\mathrm{D}}^{23}-69.5^{\circ}\left(c 0.52, \mathrm{H}_{2} \mathrm{O}\right)$} \\
\hline SI-MS: $m / z$ & $195(\mathrm{M}+\mathrm{H})^{+}, 217(\mathrm{M}+\mathrm{Na})^{+}$ \\
\hline Molecular formula & $\mathrm{C}_{6} \mathrm{H}_{7} \mathrm{~N}_{2} \mathrm{O}_{4} \mathrm{Na}\left(\mathrm{H}_{2} \mathrm{O}\right)$ \\
\hline Elemental analysis & Found: $\quad$ C $33.64, \mathrm{H} 4.31, \mathrm{~N} 12.72$, Na 11.0 \\
\hline $\mathrm{UV} \quad \lambda_{\max }^{\mathrm{H}_{2} \mathrm{O}} \mathrm{nm}(\varepsilon)$ & $253(8,060)$ \\
\hline IR $y_{\max }^{\mathrm{KBr}} \mathrm{cm}^{-1}$ & $3430,1640,1500,1410,1350$ \\
\hline${ }^{13} \mathrm{C}$ NMR: $\delta$ ppm $\left(\mathrm{D}_{2} \mathrm{O}\right)$ & $180.58(\mathrm{~s}), 177.09(\mathrm{~s}), 155.54(\mathrm{~d}), 82.85(\mathrm{~s}), 58.49(\mathrm{~d}), 26.51(\mathrm{t})$ \\
\hline
\end{tabular}

Table 5, Antifungal activity of TAN-950 A.

\begin{tabular}{lcc}
\hline \multicolumn{1}{c}{ Test organism } & & MIC $(\mu \mathrm{g} / \mathrm{ml})$ \\
\hline Candida albicans & IFO 0583 & 3.13 \\
C. parakrusei & IFO 0640 & 3.13 \\
C. parapsilosis & IFO 1396 & 1.56 \\
C. tropicalis & IFO 0006 & 0.78 \\
Torulopsis glabrata & IFO 1085 & $>100$ \\
Cryptococcus neoformans & IFO 0410 & $>100$ \\
Saccharomyces cerevisiae & IFO 0209 & 1.56 \\
Aspergillus fumigatus & IFO 6344 & $>100$ \\
Trichophyton rubrum & IFO 5467 & $>100$ \\
Microsporum gypseum & IFO 6075 & $>100$ \\
\hline
\end{tabular}

Medium: Yeast nitrogen base (supplemented with $2 \%$ glucose and $1.5 \%$ agar)

Incubation temperature and time: $28^{\circ} \mathrm{C}, 2 \sim 3$ days.

Table 7. Protective effects of TAN-950 A against systemic infection with Candida albicans TA in mice.

\begin{tabular}{lcc}
\hline \multirow{2}{*}{ Antibiotic } & \multicolumn{2}{c}{$\mathrm{ED}_{50}(\mathrm{mg} / \mathrm{kg})$} \\
\cline { 2 - 3 } & $\mathrm{sc}$ & po \\
\hline TAN-950 A & 35.5 & 100 \\
Miconazole & 25.0 & 63.1 \\
\hline
\end{tabular}

Mice $(\mathrm{n}=5)$ infected with Candida albicans TA (iv, $1 \times 10^{6}$ cells).
Table 6. Effect of amino acids on the antifungal activity of TAN-950 A.

\begin{tabular}{ccc}
\hline \multirow{2}{*}{$\begin{array}{c}\text { Amino acid } \\
(10 \mathrm{mM})\end{array}$} & \multicolumn{2}{c}{ Paper disc assay $(\mathrm{mm})$} \\
\cline { 2 - 3 } Ala & $100 \mu \mathrm{g} / \mathrm{ml}$ & $1,000 \mu \mathrm{g} / \mathrm{ml}$ \\
Val & 13 & 24 \\
Leu & 13 & 22 \\
Ile & 0 & 9 \\
Ser & 12.5 & 23 \\
Thr & 13 & 25 \\
Met & 13 & 23 \\
Phe & 13 & 23 \\
Trp & 15 & 24 \\
Pro & 13 & 23 \\
Asp & 14 & 22.5 \\
Asn & 0 & 9 \\
Glu & 12 & 25 \\
Gln & 0 & 0 \\
Lys & 13 & 24 \\
None & 14 & 23 \\
& 13 & 22.5 \\
\hline
\end{tabular}

Test organism: Saccharomyces cerevisiae IFO 0209. Medium: Yeast nitrogen base (supplemented with $2 \%$ glucose and $1.5 \%$ agar).

intravenous, intraperitoneal, subcutaneous or oral administration of single dose of $4,000 \mathrm{mg} / \mathrm{kg}$.

\section{Discussion}

TAN-950 A is a novel antifungal antibiotic produced by Streptomyces platensis A-136. Other TAN-950 A producing strains have been found among known microorganisms: Streptomyces hygroscopicus A-300 (FERM P-1312)1), Streptomyces hygroscopicus subsp. angustmyceticus IFO 3934 and Streptomyces hygroscopicus subsp. hygroscopicus IFO 14012.

Glutamic acid, aspartic acid and leucine greatly reduced the antifungal activity of TAN-950 A against Saccharomyces cerevisiae. TAN-950 A had no effect on the activity of transaminase from C. albicans or glutamate dehydrogenase from $S$. cerevisiae. As leucine is an essential amino acid for mammals, some relationship may exist between biological activity of TAN-950 A and the antagonism by amino acids. Two amino acid antibiotics have recently been reported. One is ( $S$ )-2-amino-5-hydroxy-4-oxo pentanoic acid $\left(\mathrm{HON}^{6)}\right.$ or RI-331 $1^{7)}$, which was active against yeasts in vitro and in vivo. We found that this compound 
was antagonized by methionine (data not shown). The other is $(-)-(1 R, 2 S)$-2-amino-cyclopentane-1carboxylic acid (ACPC $)^{8,9)}$, which had already been isolated as a new cyclic $\beta$-amino acid ${ }^{10)}$ which is a part of aminoacyl nucleoside antibiotic, amipurimycin ${ }^{11)}$. ACPC was antagonized by valine and isoleucine (data not shown). It may be that these types of antibiotics will become useful drugs for systemic fungal infections because of their selective toxicity.

Antagonism of TAN-950 A by glutamic acid and aspartic acid and its glutamate-analogous structure led to the idea that this compound shows affinity for excitatory amino acid receptors (kainate, quisqulate and $N$-methyl-D-aspartate subtypes) in the central nervous system. It was found to bind strongly to these receptors and also to elicit the firing of rat hippocampal CA1 neurons in vitro ${ }^{12,13)}$.

\section{Acknowledgments}

The authors wish to thank Dr. H. OKAZAKı of this division for his encouragement during this work. Thanks are also due to Dr. S. CHIBA for conducting the toxicity test, and the excellent technical assistance of K. SASABE and Y. NoHARA is gratefully acknowledged.

\section{References}

I) Tsumi, N.; M. Kobayashi, K. Nagashima, Y. Wakisaka \& K. Koizumi: A new antifungal antibiotic, trichostatin. J. Antibiotics 29: $1 \sim 6,1976$

2) Tsubotani, S.; Y. Funabashi, M. Takamoto, S. Hakoda \& S. Harada: A novel amino acid antibiotic TAN-950. Tetrahedron 47: 8079 8090, 1991

3) Color Harmony Manual, 4th Ed. Color Standards Dept., Container Corporation of America, Chicago, 1958

4) Tresner, H. D.; E. J. Backus \& J. A. HAYEs: Morphological spore types in the Streptomyces hygroscopicus-like complex. Appl. Microbiol. 15: 637 639, 1967

5) Shirling, E. B. \& D. Gottlieb: Cooperative description of type strains of Streptomyces. Int. J. Syst. Bacteriol. 22: $265 \sim 394,1972$

6) Mryake, A.: $\delta$-Hydroxy- $\gamma$-oxo-L-norvaline, a new antitubercular antibiotic. (1). Structural studies. Chem. Pharm. Bull. 8: $1071 \sim 1073,1960$

7) Yamaguchi, H.; K. Uchida, T. Hiratani, T. Nagase, N. Watanabe \& S. Omura: RI-331, a new antifungal antibiotic. Ann. N. Y. Acad. Sci. 544: 188 189, 1989

8) Oki, T.; M. Hirano, K. Tomatsu, K. Numata \& H. Kamer: Cispentacin, a new antifungal antibiotic. 11. In vitro and in vivo antifungal activities. J. Antibiotics 42; 1756 1762, 1989

9) Iwamoto, T.; E. Tsuji, M. Ezaki, A. Fuje, S. Hashimoto, M. Okuhara, M. Kohsaka, H. Imanaka, K. Kawabata, Y. Inamoto \& K. SaKanE: FR109615, a new antifungal antibiotic from Streptomyces setonii. Taxonomy, fermentation, isolation, physico-chemical properties and biological activity. J. Antibiotics 43:1 7, 1990

10) Goto, T.; Y. ToYa, T. OHGi \& T. Kondo: Structure of amipurimycin, a nucleoside antibiotic having a novel branched sugar moiety. Tetrahedron Lett. 23: $1271 \sim 1274,1982$

11) HARADA, S. \& T. KisHI: Isolation and characterization of a new nucleoside antibiotic, amipurimycin. J. Antibiotics 30: $11 \sim 16,1977$

12) Iwama, T.; Y. Nagai, S. Harada, K. Itoh \& A. Nagaoka: A novel glutamate agonist, TAN-950 A, isolated from streptomycetes. Eur. J. Pharmacol. 183: 471 472, 1990

13) Iwama, T.; Y. NAGaI, N. Tamura, S. Harada \& A. NagaOKa: A novel glutamate agonist, TAN-950 A, isolated from streptomycetes. Eur. J. Pharmacol. 197: 187 192, 1991 